\title{
AMPHETAMINE EFFECTS IN MICROTINE RODENTS: A COMPARATIVE STUDY USING MONOGAMOUS AND PROMISCUOUS VOLE SPECIES
}

\author{
J. T. CURTIS* AND Z. WANG \\ Program for Neuroscience, Department of Psychology, Florida State \\ University, Tallahassee, FL 32306, USA
}

\begin{abstract}
We compared amphetamine-induced dopamine release in the nucleus accumbens of vole species that exhibit differing mating systems to examine potential interactions between social organization and substance abuse. We found no species or regional differences in basal extracellular dopamine, however, monogamous voles had greater and longer-lasting increases in extracellular dopamine after amphetamine treatment than did promiscuous voles. We then examined whether amphetamine-induced increase in extracellular dopamine could induce pair bonds in monogamous voles. We found that, despite increasing dopamine in the nucleus accumbens, amphetamine administration did not induce pair-bonds in male prairie voles unless the animals were pretreated to preclude D1 receptor activation, which is known to inhibit pair-bond formation. These results support suggestions that social attachment and substance abuse share a common neural substrate. (c) 2007 IBRO. Published by Elsevier Ltd. All rights reserved.
\end{abstract}

Key words: mating system, pair-bond, dopamine, nucleus accumbens, addiction, microdialysis.

The genus Microtus (voles) is an ideal group of animals in which to study the processes underlying pair-bonding between adults. Although quite similar in many ways, the different vole species display a variety of mating systems ranging from promiscuity to monogamy (Dewsbury, 1981; Shapiro and Dewsbury, 1990; Cushing et al., 2001). For example, meadow (Microtus pennsylvanicus) and montane (M. montanus) voles display promiscuous mating systems and only females provide parental care. In these species, males and females occupy separate nests, defend different territories, and do not form pair-bonds between mates (Shapiro and Dewsbury, 1990; Insel et al., 1995). In contrast, prairie ( $M$. ochrogaster) and pine ( $M$. pinetorum) voles form long-term, monogamous pairbonds. In these species, both males and females provide parental care, and both sexes share a nest and vigorously defend common territory against unfamiliar conspecifics

${ }^{*}$ Correspondence to: J. T. Curtis, Department of Pharmacology and Physiology, Oklahoma State University Center for Health Sciences, 1111 West 17th Street, Tulsa, OK 74107-1898, USA. Tel: +1-918561-8471; fax: +1-918-561-8276.

E-mail address: tom.curtis@okstate.edu (J. T. Curtis).

Abbreviations: ANOVA, analysis of variance; DOPAC, 3,4-dihydroxyphenylacetic acid; ECD, electrochemical detection; EDTA, ethylenediamine tetraacetic acid; HPLC, high performance liquid chromatography; HVA, homovanillic acid; NAcc, nucleus accumbens; SNK, Student-Neuman-Keuls; VTA, ventral tegmental area.
(Getz et al., 1981; Hofmann et al., 1984; Gruder-Adams and Getz, 1985).

Evidence accumulated over the past several years has firmly established a role for central dopamine systems, especially the mesocorticolimbic "reward" pathways, in the formation and maintenance of monogamous pair-bonds. The results to date suggest that, during pair-bond formation, decreased excitatory activity in the ventral tegmental area (VTA) causes increased dopamine release in the nucleus accumbens (NAcc) (Gingrich et al., 2000; Curtis and Wang, 2005). Within the anterior shell portion of NAcc (but not in the posterior shell or the core), dopamine activates $\mathrm{D} 2$-type receptors to induce the partner preference behavior associated with pair-bonds (Gingrich et al., 2000; Aragona et al., 2003, 2006). In contrast, for individuals that already are pair-bonded, activation of D1-type dopamine receptors produces antagonistic behavior toward conspecific strangers that may serve to inhibit the formation of a second pair-bond (Aragona et al., 2006).

The mesocorticolimbic dopamine system also plays a pivotal role in drug addiction (Self et al., 1998; Yun et al., 2004), and a number of authors have suggested that addictive substances "hijack" the central processes that normally mediate social attachment (Lende and Smith, 2002; Panksepp et al., 2002; Insel, 2003). Such a suggestion is supported by observations that social isolation is a potent stimulus for self-administration of addictive substances (Howes et al., 2000). Although few studies have directly tested potential interactions between social bonding and substance abuse, many of the processes that mediate pair-bond formation appear to have functional analogues among the processes that mediate substance abuse. For example, a number of addictive substances alter excitatory inputs and/or responses in the VTA (Kalivas and Duffy, 1998; Saal et al., 2003). Further, drugs such as amphetamine produce significant increases in extracellular dopamine within the NAcc (Zocchi et al., 2003) and there often are rostral/caudal and/or core/shell differences in such responses (Heidbreder and Feldon, 1998; Di Chiara, 2002). Finally, D1- and D2-type dopamine receptors can produce opposing effects on drug-seeking behavior; D2 activation initiates drug seeking while D1 activation reduces drug-seeking (Self et al., 1996).

Since both pair-bonding and substance abuse involve the same systems, and since both processes may involve changes in neurotransmission (Saal et al., 2003; Aragona et al., 2006), it is conceivable that the two processes may exert reciprocal effects. Consistent with this possibility, strong social ties may reduce substance abuse (Recio Adrados, 1995; Ellickson et al., 1999; Bell et al., 2000) or 
may aid in recovery from previous substance abuse (Havassy et al., 1995). Furthermore, there are indications that substance abuse may negatively impact pair-bonding in humans. For example, substance abuse has been found to affect patterns of marriage and divorce (Yamaguchi and Kandel, 1985; Kandel et al., 1994; Kaestner, 1995). Unfortunately, relatively little is known about the mechanisms by which such effects may be exerted. In the present study, we used a comparative approach to examine potential species differences in responses to amphetamine administration that may be correlated with species-typical mating systems in vole species that either form or do not form pair bonds. We then tested whether amphetamine-stimulated dopamine overflow could induce pair-bonds in monogamous voles.

\section{EXPERIMENTAL PROCEDURES}

\section{Subjects}

Sexually naïve adult prairie and meadow voles were used to assess the effects of amphetamine treatment on extracellular levels of dopamine and the dopamine metabolites 3,4-dihydroxyphenylacetic acid (DOPAC) and homovanillic acid (HVA) in the NAcc. Subjects were captive bred males descended from populations from southern Illinois. Colonies were periodically outcrossed to maintain genetic variability. Pups were weaned at $\sim 21$ days of age and housed in same sex pairs in plastic shoebox style cages $(20 \times 50 \times 40 \mathrm{~cm})$ with a 14L:10D photoperiod and ad libitum food (Purina rabbit chow (Purina Mills, St. Louis, MO, USA) supplemented with black oil sunflower seeds) and water. Animals were transferred to clean cages weekly. The species and sexes were housed separately. All procedures were approved by the Florida State University Institutional Animal Care and Use Committee and were in accordance with the U.S. National Institutes of Health Guide for the Care and Use of Laboratory Animals. Every effort was made to minimize the number of animals needed and their suffering to carry out the experiments.

\section{Microdialysis probe construction and implantation}

Microdialysis probes were constructed as previously described (Curtis et al., 2003) except the active area was $1.5 \mathrm{~mm}$ and the molecular weight cutoff of the membrane was $18 \mathrm{kDa}$. Probes with this design have a dopamine recovery of $5-7 \%$. Probes were implanted stereotaxically into the left NAcc (coordinates from bregma: anterior $2.1 \mathrm{~mm}$, lateral $0.6 \mathrm{~mm}$, ventral $6.3 \mathrm{~mm}$ ) under sodium pentobarbital anesthesia ( $1 \mathrm{mg} / 10 \mathrm{~kg}$ bodyweight) and animals were allowed to recover overnight. Probes were perfused continuously at $2.3 \mu \mathrm{l} / \mathrm{min}$ with a solution isotonic for sodium, potassium, calcium, and magnesium (144 mM NaCl, $2.8 \mathrm{mM} \mathrm{KCl}$, $1.2 \mathrm{mM} \mathrm{CaCl}_{2}$, and $0.9 \mathrm{mM} \mathrm{MgCl}_{2}$ (Sved and Curtis, 1993)).

\section{Sample collection and dialysate analysis}

Dialysate samples were collected into vials containing $5 \mu \mathrm{l}$ of 0.1 $\mathrm{N}$ perchloric acid and immediately frozen at $-80^{\circ} \mathrm{C}$ until analyzed. Dialysate levels of dopamine, DOPAC, and HVA were determined using high performance liquid chromatography (HPLC) with electrochemical detection (ECD, ESA, Inc., Chelmsford, MA, USA). For each sample, $45 \mu \mathrm{l}$ of dialysate was injected on column. Analytes were separated using an Alliance Separations Module (Waters, Inc., Milford, MA, USA), and an MD-150 column (ESA, Inc.) with a mobile phase (flow rate $0.7 \mu \mathrm{l} / \mathrm{min}$ ) consisting of $75 \mathrm{mM}$ sodium dihydrogen phosphate monohydrate (EM Science, Washington, PA, USA), $1.7 \mathrm{mM}$ 1-octanesulfonic acid sodium salt (Sigma, St. Louis, MO, USA), 0.01\% triethylamine (Aldrich, USA),
$25 \mu \mathrm{M}$ EDTA (Fisher, Pittsburgh, PA, USA), pH adjusted to 3.0 with $\sim 2 \mathrm{ml} / \mathrm{l}$ of $85 \%$ phosphoric acid (Fisher). Analyte detection was achieved by first oxidizing the samples at $400 \mathrm{mV}$, followed by reduction at $-350 \mathrm{mV}$. DOPAC and HVA were quantified using oxidation peaks at low gain, while dopamine was quantified using reduction peaks at high gain. Peak areas were converted to amounts (pg analyte/45 $\mu$, not corrected for probe recovery) by comparisons with peaks produced using standards of known concentration. The quantification limit for dopamine was $\sim 2 \mathrm{pg} / 45 \mu \mathrm{l}$ injection, and the detection limit was $\sim 0.5 \mathrm{pg} / 45 \mu \mathrm{l}$ injection.

\section{Acute effects of peripheral amphetamine treatment}

Following overnight recovery, four 20-minute baseline samples were collected, after which each male received an i.p. injection either of $200 \mu \mathrm{l} / 40 \mathrm{~g}$ body weight of saline or of saline containing $3 \mathrm{mg} / \mathrm{kg}$ amphetamine. Samples then were collected at 20-minute intervals for $3 \mathrm{~h}$ and analyzed using HPLC-ECD.

\section{Effects of amphetamine within NAcc}

Two additional groups of males of each species were used to examine the effects of amphetamine administered directly into the NAcc via reverse microdialysis while collecting samples for dopamine analysis. In the first group, after baseline sampling, the dialysis fluid was switched to one containing $1 \mathrm{mM}$ amphetamine for three 20-minute sampling periods followed by return to standard dialysis fluid for another $2 \mathrm{~h}$. This experiment was designed to assess maximally stimulated short-term responses to amphetamine treatment. In the second group, after baseline sampling, the dialysis fluid was replaced with one containing $100 \mu \mathrm{M}$ amphetamine. Thereafter, amphetamine levels were ramped up by increasing the concentration after every second sample. Amphetamine concentrations tested were $0,100,200,400$, and $800 \mu \mathrm{M}$ and $1 \mathrm{mM}$. Since it required approximately $12 \mathrm{~min}$ for a new concentration of amphetamine to reach the active area of the probe following changes between solutions, the first sample at each concentration was a transitional sample, while the target concentration of amphetamine was present for 3 min prior to, and then throughout, the second sampling period at each concentration. This experiment was designed to test longer-term sustained responses to amphetamine treatment.

\section{Assessment of microdialysis probe placement}

At the end of the microdialysis sampling period, animals were given an overdose of sodium pentobarbital and the brains were removed for assessment of probe placements. Brains were sectioned at $40 \mu \mathrm{m}$ on a cryostat and sections through the NAcc were thaw-mounted onto microscope slides. Probe placement was assessed in freshly mounted tissue, or in some cases, in Nisslstained tissue. Determination of placement was made using the regional delineations described by Paxinos and Watson (1998). The genu of the corpus callosum was used to delineate anterior from posterior placement within the NAcc. Probes with tracks medial to the lateral ventricle were considered to be in the NAcc shell, while those with tracks lateral to the ventricle were considered to be in the NAcc core. For inclusion in the study, at least $80 \%$ of the active area had to be within either the core or shell. Animals with probes that spanned significant portions of more than one region were excluded.

\section{Effects of amphetamine treatment on partner preference formation}

In the first experiment, male prairie voles ( $n=7-10 /$ group) received i.p. injections of $200 \mu \mathrm{l} / 40 \mathrm{~g}$ body weight of saline or of saline containing $0.5,1.0$, or $3.0 \mathrm{mg} / \mathrm{kg}$ of amphetamine. Each male then was paired with a sexually non-receptive, ovariecto- 
mized female of similar size and age for $6 \mathrm{~h}$ of non-sexual cohabitation. Interactions between members of each pair were videotaped for subsequent verification that mating did not occur during cohabitation and to assess potential behavioral deficits caused by drug treatment.

Immediately following the 6-h cohabitation period, each male was tested for a partner preference (Williams et al., 1992). The apparatus for the partner preference test consisted of a neutral cage $(20 \times 50 \times 40 \mathrm{~cm})$ connected by tubes to two identical cages, one of which contained the familiar female partner while the other contained an unfamiliar female with which the male had never interacted. Females were tethered in their respective cages and thus had no contact with each other, while the male subject had unfettered access to all three cages. A customized computer program (R. Henderson, Florida State University) using a series of light-beams across the connecting tubes monitored the movement of the male among the cages. Testing lasted for $3 \mathrm{~h}$. Again, the animals were videotaped for detailed behavioral analysis. Variables assessed included the time spent in close contact with each stimulus female as a measure of affiliative behavior, the amount of time spent in the neutral cage as a measure of general non-social behavior, and the number of crossings between cages as a measure of overall activity.

In the second experiment, male prairie voles were injected (i.p.) with $100 \mu \mathrm{g} / \mathrm{kg}$ of SCH23390, a D1-type dopamine receptor antagonist. Thirty minutes later each male received either vehicle or $1 \mathrm{mg} / \mathrm{kg}$ amphetamine (i.p.), was paired with a female for $6 \mathrm{~h}$, and then tested for a partner preference as described above.

\section{Data analysis}

Absolute amounts of dialysate dopamine were used for species, regional, and between treatment-groups comparisons of baseline amounts by analysis of variance (ANOVA) (Statistica). For these comparisons, the mean of the four baseline samples for each animal was used. Detailed descriptions of the various combinations of factors used in the ANOVAs are presented with the results. Species comparisons for basal DOPAC and HVA were made using independent $t$-tests.

For all other comparisons, the amounts of dopamine or its metabolites in each baseline and post-amphetamine sample were expressed as a percentage of the mean baseline amount. These values then were used in repeated measures ANOVAs with change in analyte amount across time as the repeated measure. In a small number of cases, it was necessary to estimate values for missing samples to use repeated measures analyses. In these cases, the mean of all samples for the appropriate time period was calculated. Median interpolation then was used to generate a second estimate of the missing value. The mean of these two values then was used to replace the missing sample value. No animal included in the analyses had more than one sample value generated in this way. Student-Neuman-Keuls (SNK) post hoc analyses were used to further examine significant main effects or interactions $(P<0.05)$. Again, descriptions of the various factors used in the ANOVAs are presented with the results. For a sample to be considered significantly different from baseline, that sample had to be significantly different from at least three of the four baseline samples as assessed by SNK post hoc analysis. Treatment effects on partner preferences were assessed using paired $t$-tests to compare the group means for amount of time spent in close contact with the partner vs. with the stranger. Examinations of other behaviors during the partner preference test were made using ANOVAs followed by SNK post hoc analyses when significant main effects or interactions were found.

\section{RESULTS}

All animals were at least 66 days old and thus sexually mature at the time of the experiments. The mean ages of animals did not differ either between species $\left(F_{1,49}=0.17\right.$, $P=0.68)$ or treatment groups $\left(F_{4,49}=0.01, P=0.94\right)$.

\section{Species, region, and sub-nucleus comparisons of basal dopamine levels}

A three-way ANOVA was used to compare baseline dopamine levels. A total of 48 animals met the probe placement criteria (Fig. 1) for inclusion in the species $(n=20$ meadow voles; 28 prairie voles), region ( $n=29$ rostral; 19 caudal), and sub-nucleus ( $n=18$ core; 30 shell) comparisons. Basal extracellular dopamine (Table 1) did not differ between species $\left(F_{1,40}=0.08, P=0.78\right)$, sub-nuclei $\left(F_{1,40}=0.85\right.$, $P=0.36)$, or rostral/caudal levels $\left(F_{1,40}=0.33, P=0.57\right)$ and there were no statistically significant interactions.

\section{Species comparisons after peripheral amphetamine administration}

Male meadow and prairie voles received either of $200 \mu / / 40 \mathrm{~g}$ body weight of saline vehicle i.p. ( $n=5$ for each species) or of saline containing $3 \mathrm{mg} / \mathrm{kg}$ of amphetamine ( $n=8$ meadow voles, six prairie voles). Two-way ANOVA using species and treatment as factors revealed no differences in baseline dopamine levels (Table 2) either between species $\left(F_{1,23}=1.29\right.$, $P=0.27)$ or between treatment groups $\left(F_{1,23}=0.97, P=0.33\right)$, although there was a significant interaction $\left(F_{1,23}=5.11\right.$, $P=0.04$ ). Post hoc assessment of the interaction revealed no significant pair-wise differences within species or between treatment groups although there was a marginal difference between the amphetamine and saline groups for meadow voles $(P=0.08)$.

Peripheral administration of $3 \mathrm{mg} / \mathrm{kg}$ amphetamine increased extracellular dopamine levels in the NAcc in both species $\left(F_{1,15}=7.27, P<0.02\right)$; however, the magnitude and duration of the increase differed (species comparison $F_{1,15}=17.10, P<0.01$; species by time interaction $F_{12,180}=2.24, P<0.02$ ) between species (Fig. 2). In prairie voles, amphetamine increased extracellular dopamine to about $275 \%$ of baseline, and although there was a gradual decline, dopamine levels remained significantly above baseline for at least five 20-minute sampling periods. In contrast, amphetamine increased extracellular dopamine only to about $175 \%$ of baseline in meadow voles, and levels were significantly elevated over baseline only for 40 $\min$. Dopamine levels were unchanged after saline treatment in both species. The pattern was seen for absolute amounts of dopamine as well as for percent change from baseline. When the absolute amounts of dopamine recovered in each sample were compared between prairie and meadow voles that received amphetamine treatment, there was a significant species effect $\left(F_{13,117}=8.09\right.$, $P<0.001$ ). Comparing individual time points, there were no species differences between any of the baseline values, but prairie voles displayed greater absolute amounts of extracellular dopamine $(30.5 \pm 9.8 \mathrm{pg} / \mathrm{sample})$ after amphetamine administration than did meadow voles (18.7 $\pm 4.2 \mathrm{pg} / \mathrm{sample})$. 

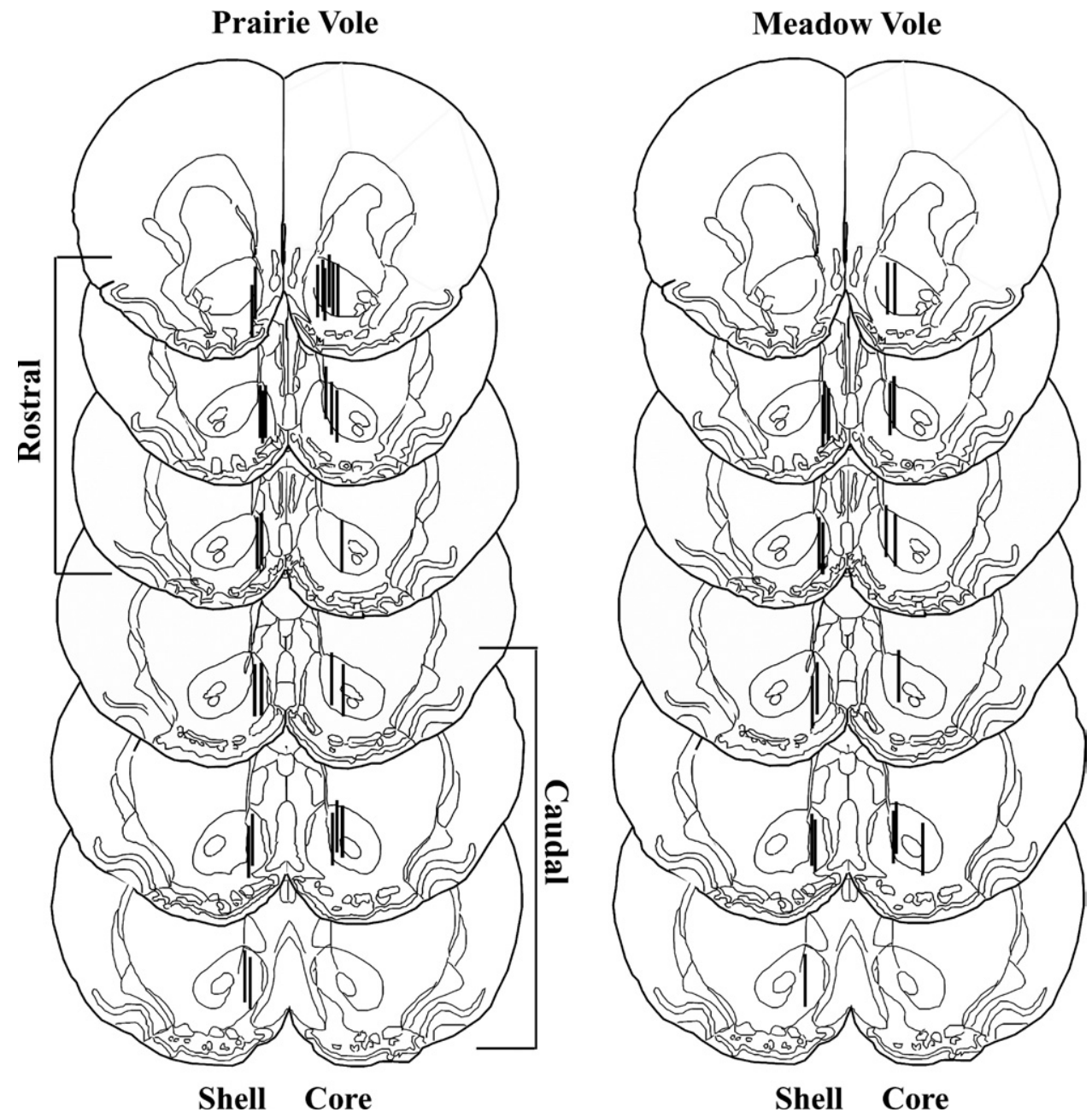

Fig. 1. Microdialysis probe placements. Each vertical black bar represents the active area of a single microdialysis probe based on postmortem probe placement assessments. Although all probes were placed in the left NAcc, for presentation purposes, shell placements (left hemisphere) and core placements (right hemisphere) are combined at each rostral-caudal level. Schematic brain sections were redrawn from Paxinos and Watson (1998).

\section{Species comparisons for site-specific amphetamine administration}

Site-specific administration of $1 \mathrm{mM}$ amphetamine into the NAcc via reverse microdialysis significantly increased extracellular dopamine levels to approximately $2000 \%$ of baseline in both species ( $n=3$ meadow voles and six prairie voles; Fig. $3 \mathrm{~A}$ ). Further, the magnitudes and durations of the responses were similar in both species. Similarly, no species differences were found when the amphetamine concentration was slowly increased over several hours $(n=4$ meadow voles and 4 prairie voles; Fig. 3B). In this experiment, reverse dialysis of $100 \mu \mathrm{M}$ amphetamine increased extracellular dopamine to about $700 \%$ of baseline. That level of do-

Table 1. Species and sub-nucleus comparisons of basal extracellular dopamine within the NAcc

\begin{tabular}{|c|c|c|c|c|c|c|c|c|}
\hline \multicolumn{4}{|l|}{ Prairie vole } & \multicolumn{4}{|l|}{ Meadow vole } & \multirow{2}{*}{$\frac{P \text {-value }}{0.78}$} \\
\hline $13.5 \pm 1.6(28)$ & & & & $13.3 \pm 2.2(20)$ & & & & \\
\hline Core & & Shell & & Core & & Shell & & \\
\hline $13.8 \pm 2.9(11)$ & & $13.3 \pm 2.0(17)$ & & $16.8 \pm 4.7(7)$ & & $11.5 \pm 2.5(13)$ & & 0.36 \\
\hline Rostral & Caudal & Rostral & Caudal & Rostral & Caudal & Rostral & Caudal & \\
\hline $16.3 \pm 5.2(6)$ & $10.8 \pm 2.2(5)$ & $13.8 \pm 2.3(12)$ & $12.0 \pm 4.4(5)$ & $20.0 \pm 7.4(4)$ & $12.5 \pm 3.2(3)$ & $7.6 \pm 2.0(7)$ & $16.0 \pm 4.7(6)$ & 0.57 \\
\hline
\end{tabular}

Values are $\mathrm{pg} / 45 \mu \mathrm{l}$ of dialysate (mean \pm S.E.M.); numbers of animals in each group are shown in parentheses. $P$-values are given for the main effects from a three-way ANOVA comparing species, anterior/posterior level, and core/shell comparisons. 
Table 2. Species and treatment group comparisons of basal extracellular dopamine within the NAcc

\begin{tabular}{llll}
\hline Prairie vole & & Meadow vole & \\
\hline $10.8 \pm 2.0(12)$ & $\frac{\text { Amphetamine }}{12.7 \pm 2.3(13)}$ & $\frac{P \text {-value }}{0.27}$ \\
$\frac{\text { Saline }}{8.8 \pm 2.0(5)}$ & $\frac{\text { Saline }}{12.3 \pm 3.1(7)}$ & $\frac{\text { Amphetamine }}{9.2 \pm 2.0(5)}$ & $0.3 .6(8)$ \\
\hline
\end{tabular}

Values are $\mathrm{pg} / 45 \mu$ l of dialysate (mean \pm S.E.M.); numbers of animals in parentheses. $P$-values are given for the main effects from a two-way ANOVA comparing species and treatment group baselines.

pamine release was sustained, but did not increase further despite an eventual 10-fold increase in the amphetamine concentration. There were no differences in basal extracellular dopamine either between experimental groups $\left(F_{1,13}=0.001, P=0.97\right)$ or between species $\left(F_{1,13}=0.001, P=0.98\right)$.

\section{Amphetamine effects on dopamine metabolites in NAcc}

Overall there were no species differences in baseline levels of either DOPAC (prairie 1159.7 \pm 295.9 , meadow $1011.2 \pm 171.4 ; t=0.56, P=0.58$ ) or HVA (prairie 1033.5 \pm 162.2, meadow 976.8 $\pm 165.7 ; t=0.24, P=0.81$ ). Peripheral administration of amphetamine caused a significant decrease in extracellular levels of DOPAC $\left(F_{12,108}=13.54\right.$, $P<0.001$ ) (Fig. 4A). As with dopamine, the magnitude of the response was smaller and the duration shorter in meadow voles compared with that for prairie voles. Sitespecific administration of $1 \mathrm{mM}$ amphetamine into NAcc via reverse dialysis significantly decreased extracellular DOPAC levels $\left(F_{12,132}=23.06, P<0.001\right)$ in both species (Fig. 4B). Levels remained depressed throughout the course of the test despite the fact that the amphetamine solution was replaced with normal dialysis fluid after only three samples. Ramped increases of amphetamine into the NAcc produced a similar pattern of decrease in extracellular DOPAC levels $\left(F_{12,48}=15.70, P<0.001\right)$; however, this administration protocol produced a significant effect of species $\left(F_{1,4}=17.18, P<0.02\right)$ and a species by treatment interaction $\left(F_{12,48}=2.24, P<0.03\right)$. Although both groups displayed a decrease in extracellular DOPAC, the effect was more robust in meadow voles (Fig. 4C). Extracellular levels of HVA were unaffected by either peripheral or site-specific administration in both species (all $P$-values $>0.20$, data not shown).

\section{Amphetamine effects on pair-bonding}

As expected, saline-treated males exposed to an ovariectomized female for $6 \mathrm{~h}$ of non-sexual contact displayed non-selective affiliation (Fig. 5A) when subsequently given a choice between the familiar female and an unfamiliar ovariectomized female ( $t=0.69, P=0.51)$. Amphetamine treatment at any of the three doses also failed to induce a partner preference $(0.5 \mathrm{mg} / \mathrm{kg}: t=0.71, P=0.50 ; 1.0 \mathrm{mg} / \mathrm{kg}$ : $t=1.26, P=0.29 ; 3 \mathrm{mg} / \mathrm{kg}: t=0.05, P=0.96)$. However, when $1 \mathrm{mg} / \mathrm{kg}$ of amphetamine was administered after

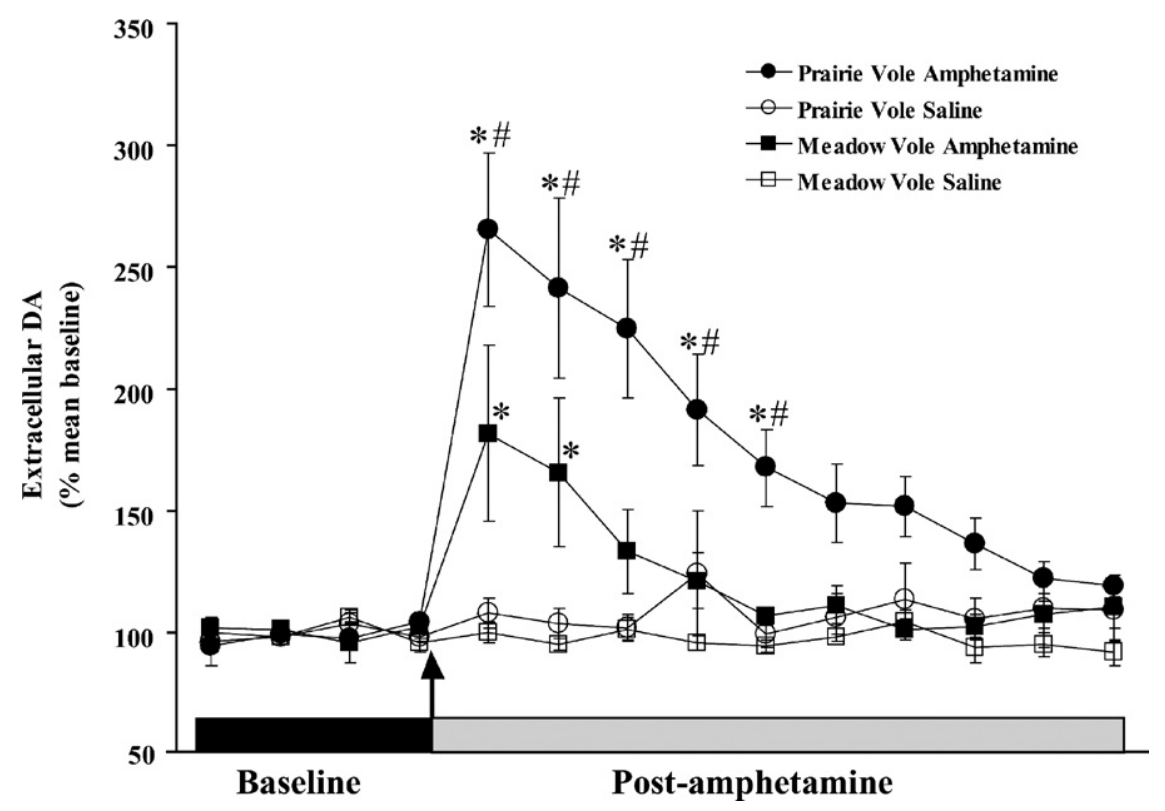

Fig. 2. Peripheral administration of amphetamine increased extracellular dopamine within the NAcc. This response was greater in monogamous prairie voles (filled circles) than in promiscuous meadow voles (filled squares). Saline injections had no effect in either species (open symbols). Arrow indicates time of injection. * Significant difference from the within-species baseline. ${ }^{\#}$ Sample periods for which there are significant species differences. 

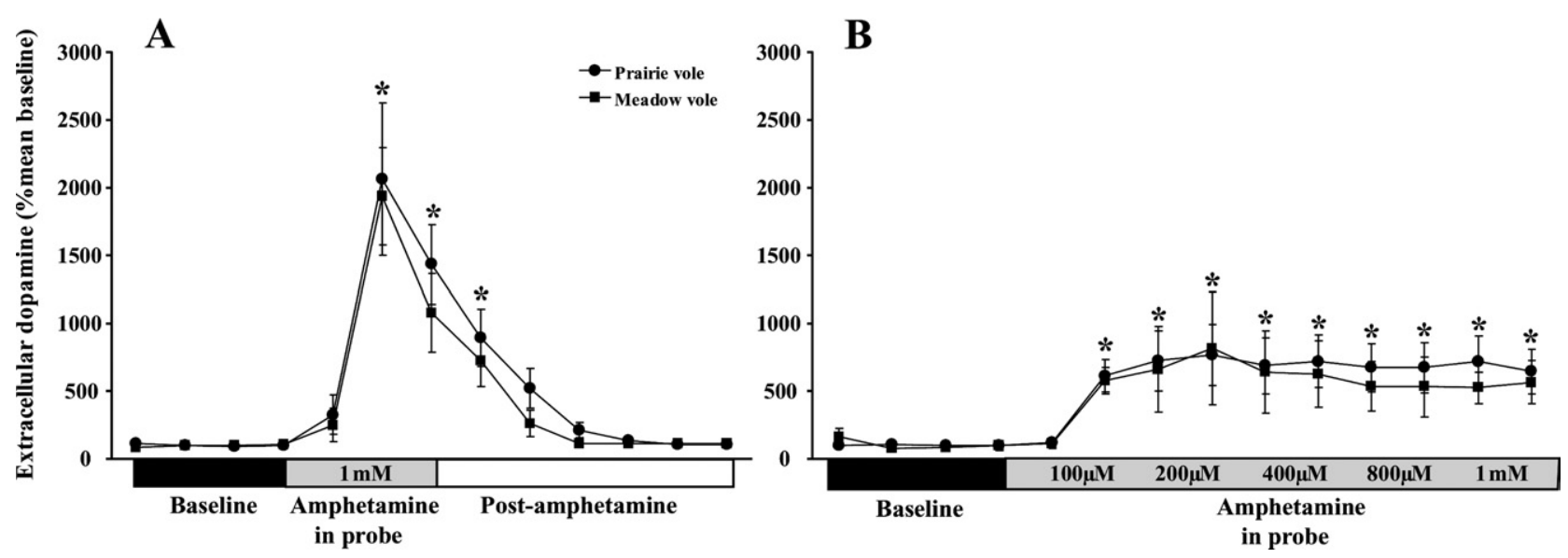

Fig. 3. Reverse dialysis administration of amphetamine into the NAcc induced significant increases in extracellular dopamine levels in both monogamous and promiscuous vole species. (A) Species comparison of responses to concentrated amphetamine in dialysate. (B) Species comparison of responses to gradually increasing amphetamine concentrations. No species differences were noted; * significant increase over baseline for both species. The first sample at each concentration includes the transition between concentrations. Ordinate scale is the same in both panels to facilitate comparison of the responses to $1 \mathrm{mM}$ amphetamine under each administration protocol.

pre-treatment with the D1-type dopamine receptor antagonist SCH23390 (Fig. 5B), males displayed a preference for contact with the partner $(t=2.46, P<0.05)$. Animals given $\mathrm{SCH} 23390$ followed by a saline injection displayed non-selective affiliative behavior similar to that seen for other control males $(t=-0.43, P=0.68)$. There were no apparent behavioral deficits associated with any of the treatments (Table 3). Specifically, total time spent in close contact with the two females did not differ between groups $\left(F_{5,46}=0.46, P=0.80\right)$. Non-social behaviors such as time spent in the neutral cage $\left(F_{5,46}=0.25, P=0.94\right)$ and locomotor activity $\left(F_{5,46}=1.46, P=0.23\right)$ also were unaffected by treatment.

\section{DISCUSSION}

Comparative studies using voles have identified neuroanatomical and neurochemical differences that are well-correlated with species-specific mating systems (Insel and Shapiro, 1992; Wang, 1995; Lim et al., 2005). Further, several studies have shown that pair-bonding involves re-organization of some brain regions (Bamshad et al., 1993; Wang et al., 1994), most notably in portions of the mesolimbic dopamine pathway (Aragona et al., 2006). Since some of the same areas that mediate pair bonding also are important in substance abuse, we examined whether the species differences that produce the various mating systems among voles also produce species-specific responses to drugs of abuse.

\section{Species differences in NAcc dopamine response to amphetamine}

Male prairie voles had a more robust and longer-lasting increase in extracellular dopamine in the NAcc after peripheral amphetamine administration than did meadow voles. This observation suggests that monogamous voles may be more sensitive to the effects of amphetamine than are promiscuous species. Thus, in monogamous species, the positive reinforcement effects of drugs such as amphetamine may be more robust than those experienced by promiscuous species. Alternatively, the species differences in drug-induced dopamine release could indicate that an amphetamine dose that is reinforcing for promiscuous voles could produce such an intense response in monogamous voles as to be aversive (Orsini et al., 2004). In either case, changes in central pathways associated with substance abuse could be magnified in monogamous species.

We found no regional differences in basal extracellular dopamine levels in prairie and meadow voles, nor did we see any species differences when amphetamine was administered directly into the NAcc. These results provide further evidence that species differences in vole mating systems likely do not result from fundamental differences in dopamine neurocircuitry (Curtis et al., 2003). Rather, the species differences likely arise from subtle differences in dopamine release or clearance, in the distribution or density of dopamine receptors, or in dopamine interactions with other neurotransmitter systems (Liu and Wang, 2003; Lim and Young, 2004). Since amphetamine targets the dopamine transporter (Jones et al., 1998), the lack of species differences in stimulated levels in response to site-specific amphetamine administration suggests that the species do not differ in the density or function of dopamine transporters. Superficially, the lack of species differences in response to sustained amphetamine administration also suggests that the species do not differ in their capacities to produce dopamine. However, the species difference in extracellular DOPAC after sustained amphetamine treatment might argue against such an interpretation (Jones et al., 1998). As with dopamine, the effects of amphetamine on extracellular DOPAC were greater and of longer duration in prairie voles than in meadow voles after peripheral administration, but when amphetamine was administered directly into NAcc, there was a greater DOPAC decrease in meadow voles. Given the lack of species differences in 

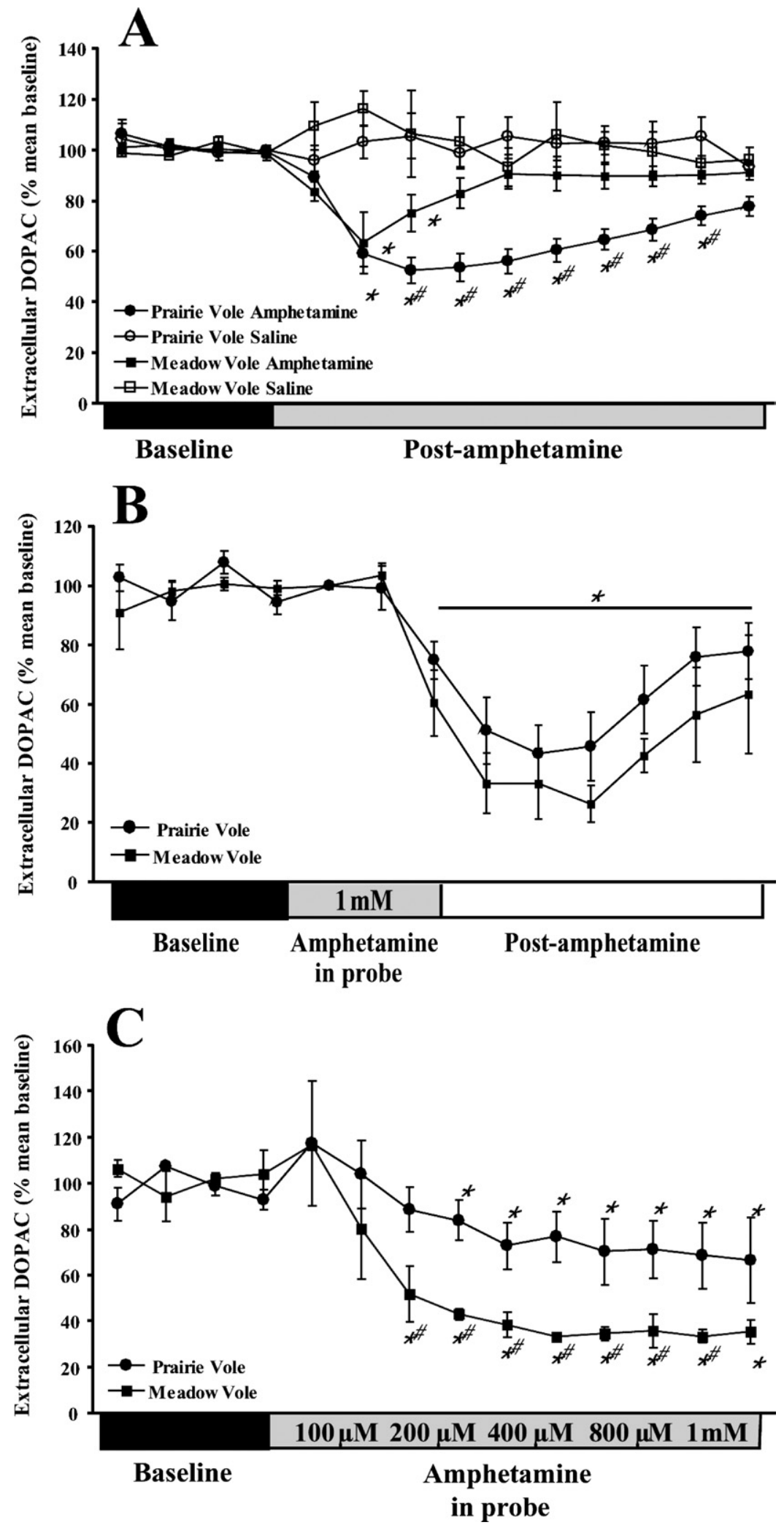

Fig. 4. Amphetamine effects on extracellular levels of DOPAC. Peripheral administration of $3 \mathrm{mg} / \mathrm{kg}$ amphetamine significantly reduced NAcc DOPAC in both species, although the effect was greater in prairie voles (A). The effects of site specific administration of amphetamine via reverse dialysis within NAcc on extracellular DOPAC depended on the administration protocol. No species differences were found after a concentrated amphetamine dose (B), while a ramped administration paradigm produced greater effects in meadow voles (C). ${ }^{*}$ Significant difference from the within species baseline. \# Sample periods for which there are significant species differences. 


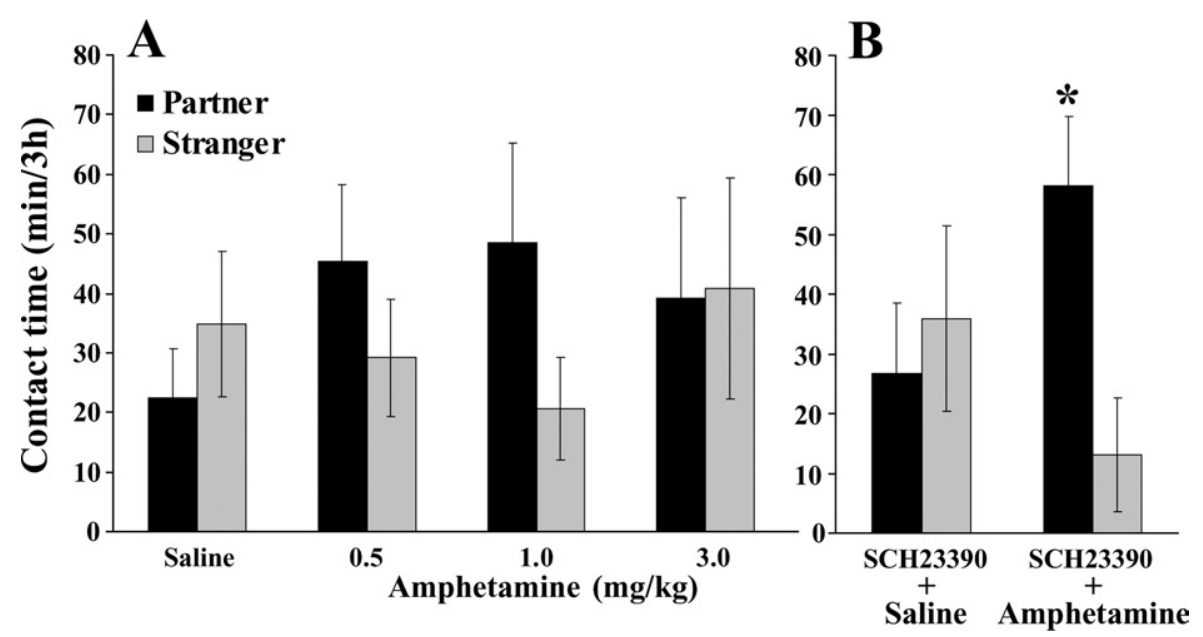

Fig. 5. Amphetamine-induced increases in NAcc dopamine did not induce partner preferences in male prairie voles unless animals were pre-treated to preclude D1-type dopamine receptor activation. At all doses of amphetamine tested, the amounts of time spent in close contact with the familiar partner and with the stranger were equivalent (A). In contrast, when males were pretreated with a D1 receptor antagonist, $1 \mathrm{mg} / \mathrm{kg}$ of amphetamine induced a significant preference for contact with the familiar partner (B). * Significantly more time spent in contact with the familiar partner.

extracellular dopamine after amphetamine treatment in the same animals, it is unclear how to interpret these results. One possibility is that the greater reduction in extracellular DOPAC after site-specific amphetamine administration in meadow voles may reflect lower levels of intracellular dopamine in promiscuous voles. It must be noted that we cannot rule out the possibility that the species differences seen after peripheral amphetamine administration may simply reflect species differences in the ability to metabolize amphetamine.

\section{Amphetamine and pair-bonding}

The second major finding in the present study was that amphetamine treatment did not induce partner preferences in the absence of D1 dopamine receptor blockade. On the surface, this is an unexpected result. Increases in extracellular dopamine in NAcc are correlated with pairbond formation (Gingrich et al., 2000), and short-term activation of the mesolimbic pathway is sufficient to induce partner preferences (Gingrich et al., 2000; Aragona et al., 2003, 2006; Curtis and Wang, 2005). Since the microdialysis results show that amphetamine treatment increases dopamine release in prairie voles, a priori one might predict that amphetamine treatment would induce pair-bonds. Why then did amphetamine fail to induce partner preferences?

The answer may lie in the relative roles that activation of D1- and D2-type dopamine receptors play in pair bond- ing (Aragona et al., 2003). Early studies of dopamine involvement in pair-bonding suggested that, while activation of D2 receptors facilitated pair-bond formation, D1 receptors were not involved in this process (Wang et al., 1999). Subsequent work, however, has shown that activation of D1-type dopamine receptors actually prevents the formation of partner preferences induced either by pharmacological activation of D2 receptors or by mating (Aragona et al., 2006). This opposing modulation is exemplified by the fact that the dopamine receptor agonist apomorphine induces pair-bonds in a dose-dependent fashion (Aragona et al., 2006). At low concentrations apomorphine binds primarily to D2 receptors, facilitating pair-bonding. However, at higher concentrations, apomorphine binds to D1 receptors as well, negating the effects of D2 activation. A similar result would be expected for drugs such as amphetamine that produce essentially global increases in extracellular dopamine (Becker, 1990; Young and Rees, 1998; Yurek et al., 1998). Such an increase is unlikely to produce preferential activation of only a specific subset of dopamine receptors, but rather would elicit non-specific activation of all dopamine receptors. Since concurrent activation of D1 and D2 receptors is inimical to pair-bonding (Aragona et al., 2006), amphetamine-induced dopamine release does not induce partner preferences in the absence of D1 blockade. However, prior treatment with a D1 antagonist results in primarily D2 activation after amphetamine, and thus

Table 3. Treatment group comparisons for general social and non-social behaviors by male prairie voles during 3-h partner preference tests

\begin{tabular}{|c|c|c|c|c|c|c|}
\hline \multirow[t]{2}{*}{ Behavior } & \multirow{2}{*}{$\begin{array}{l}\text { Saline } \\
(n=8)\end{array}$} & \multicolumn{3}{|c|}{ Amphetamine $(\mathrm{mg} / \mathrm{kg})$} & \multicolumn{2}{|c|}{$\mathrm{SCH} 23390,100 \mu \mathrm{g} / \mathrm{kg}$} \\
\hline & & $0.5(n=7)$ & $1.0(n=0)$ & $3.0(n=7)$ & + Saline $(n=7)$ & $\begin{array}{l}\text { + Amphetamine, } \\
1.0 \mathrm{mg} / \mathrm{kg}(n=8)\end{array}$ \\
\hline Contact time (min) & $57.4 \pm 10.5$ & $74.4 \pm 9.2$ & $69.0 \pm 12.9$ & $80.0 \pm 11.3$ & $71.2 \pm 10.6$ & $62.7 \pm 15.6$ \\
\hline Time in neutral cage $(\mathrm{min})$ & $33.8 \pm 2.8$ & $31.5 \pm 4.2$ & $28.8 \pm 5.7$ & $34.0 \pm 12.0$ & $36.3 \pm 7.3$ & $28.8 \pm 3.3$ \\
\hline Locomotion (cage entries) & $326.4 \pm 49.8$ & $253.7 \pm 38.9$ & $237.5 \pm 43.7$ & $164.6 \pm 20.3$ & $218.4 \pm 51.2$ & $223.1 \pm 44.8$ \\
\hline
\end{tabular}


partner preferences are expressed after concurrent treatment with both drugs.

These results also help to elaborate the role of D1 receptors in pair-bonding. Although there is good evidence that D1 activation inhibits pair bond formation and plays an important role in rejecting potential new mates (Aragona et al., 2006; Curtis et al., 2006), previously, it was unknown whether blockade of D1 receptors alone was sufficient to induce pair-bonds. In the present study, D1 blockade alone did not induce partner preference formation. Thus, in the absence of D2 activation, simply reducing D1 activation is not sufficient for pair-bonding to occur.

It should be noted that the effects of D1 blockade did not result from behavioral suppression during the choice test. In one study, the dose of D1 antagonist used here produced some short-term motor impairment (Weatherford et al., 1990). However, we found no apparent motor deficits; treated males did not differ from control males in non-social behaviors during the partner preference test. This may reflect differences in the timing of tests. In the present study there were at least 30 min between drug injection and the beginning of behavioral interactions and the critical dependent variable was not assessed until 6-9 $\mathrm{h}$ after drug treatment. Thus, the increase in time spent with the familiar partner was not the result of changes in overall social contact, locomotor activity, or time spent in isolation. Rather, the difference in affiliative behavior was driven by a switch from non-selective affiliation to a preference for contact with the partner. It also is possible that D1 blockade altered behavior during the initial cohabitation period. Males appeared to interact normally with females during cohabitation. However, the typical behavior during this period is for pairs to huddle quietly in one corner of the cage for the majority of the cohabitation period. Thus behavioral suppression would be difficult to detect without more invasive measures.

As noted above, addictive substances often target the same central pathways that modulate social bonding. Although the present study focused on the mesolimbic dopamine system, it should be noted that central opiate systems play a role in social bonding (Panksepp et al., 1997), and also can be targets of addictive substances (De Vries and Shippenberg, 2002) in part via interactions with dopamine (Koob et al., 1998). If reciprocal effects between substance abuse and social bonding occur, changes in central functioning associated with responses to drugs could affect pair-bond formation, and vice versa. For example, drugs of abuse can alter signaling pathways associated with D1 receptors (Nestler, 2001), the activation of which impairs social bonding (Aragona et al., 2006). Thus, in monogamous voles, drugs of abuse may produce central changes that subsequently make it more difficult to form social bonds. How this might translate to other species is yet to be determined, however, these results suggest that substance abuse could have significant consequences for human bonding.

Acknowledgments-This work was supported by NIH grants HD48462 (J.T.C.) and MH58616 and DA19627 (Z.W.).

\section{REFERENCES}

Aragona BJ, Liu Y, Curtis JT, Stephan FK, Wang Z (2003) A critical role for nucleus accumbens dopamine in partner-preference formation in male prairie voles. J Neurosci 23:3483-3490.

Aragona BJ, Liu Y, Yu YJ, Curtis JT, Detwiler JM, Insel TR, Wang Z (2006) Nucleus accumbens dopamine differentially mediates the formation and maintenance of monogamous pair bonds. Nat Neurosci 9:133-139.

Bamshad M, Novak MA, De Vries GJ (1993) Sex and species differences in the vasopressin innervation of sexually naive and parental prairie voles, Microtus ochrogaster and meadow voles, Microtus pennsylvanicus. J Neuroendocrinol 5:247-255.

Becker JB (1990) Estrogen rapidly potentiates amphetamine-induced striatal dopamine release and rotational behavior during microdialysis. Neurosci Lett 118:169-171.

Bell NJ, Forthun LF, Sun S-W (2000) Attachment, adolescent competencies, and substance use: Developmental considerations in the study of risk behaviors. Subst Use Misuse 35:1177-1206.

Curtis JT, Liu Y, Aragona BJ, Wang ZX (2006) Dopamine and monogamy. Brain Res 1126:76-90.

Curtis JT, Stowe JR, Wang Z (2003) Differential effects of intraspecific interactions on the striatal dopamine system in social and nonsocial voles. Neuroscience 118:1165-1173.

Curtis JT, Wang Z (2005) Ventral tegmental area involvement in pair bonding in male prairie voles. Physiol Behav 86:338-346.

Cushing BS, Martin JO, Young LJ, Carter CS (2001) The effects of peptides on partner preference formation are predicted by habitat in prairie voles. Horm Behav 39:48-58.

De Vries TJ, Shippenberg TS (2002) Neural systems underlying opiate addiction. J Neurosci 22:3321-3325.

Dewsbury DA (1981) An exercise in the prediction of monogamy in the field from laboratory data on 42 species of muroid rodents. Biologist 63:138-162.

Di Chiara G (2002) Nucleus accumbens shell and core dopamine: differential role in behavior and addiction. Behav Brain Res 137:75-114.

Ellickson PL, Collins RL, Bell RM (1999) Adolescent use of illicit drugs other than marijuana: How important is social bonding and for which ethic groups? Subst Use Misuse 34:317-346.

Getz LL, Carter CS, Gavish L (1981) The mating system of the prairie vole, Microtus ochrogaster. field and laboratory evidence for pairbonding. Behav Ecol Sociobiol 8:189-194.

Gingrich B, Liu Y, Cascio C, Wang Z, Insel TR (2000) Dopamine D2 receptors in the nucleus accumbens are important for social attachment in female prairie voles (Microtus ochrogaster). Behav Neurosci 114:173-183.

Gruder-Adams S, Getz LL (1985) Comparison of the mating system and paternal behavior in Microtus ochrogaster and Microtus pennsylvanicus. J Mammal 66:165-167.

Havassy BE, Wasserman DA, Hall SM (1995) Social relationships and abstinence from cocaine in an American treatment sample. Addiction 90:699-710.

Heidbreder C, Feldon J (1998) Amphetamine-induced neurochemical and locomotor responses are expressed differentially across the anteroposterior axis of the core and shell subterritories of the nucleus accumbens. Synapse 29:310-322.

Hofmann JE, Getz LL, Gavish L (1984) Home range overlap and nest cohabitation of male and female prairie voles. Am Midl Nat 112:314-319.

Howes SR, Dalley JW, Morrison CH, Robbins TW, Everitt BJ (2000) Leftward shift in the acquisition of cocaine self-administration in isolation-reared rats: relationship to extracellular levels of dopamine, serotonin and glutamate in the nucleus accumbens and amygdala-striatal FOS expression. Psychopharmacology (Berl) 151:55-63.

Insel TR (2003) Is social attachment an addictive disorder? Physiol Behav 79:351-357. 
Insel TR, Preston S, Winslow JT (1995) Mating in the monogamous male: behavioral consequences. Physiol Behav 57:615-627.

Insel TR, Shapiro LE (1992) Oxytocin receptor distribution reflects social organization in monogamous and polygamous voles. Proc Natl Acad Sci U S A 89:5981-5985.

Jones SR, Gainetdinov RR, Jaber M, Giros B, Wightman RM, Caron MG (1998) Profound neuronal plasticity in response to inactivation of the dopamine transporter. Proc Natl Acad Sci U S A 95: 4029-4034.

Kaestner R (1995) The effects of cocaine and marijuana use on marriage and marital stability. National Bureau of Economic Research Working Paper No. 5038.

Kalivas PW, Duffy P (1998) Repeated cocaine administration alters extracellular glutamate in the ventral tegmental area. J Neurochem 70:1497-1502.

Kandel DB, Rosenbaum E, Chen K (1994) Impact of maternal druguse and life experiences on preadolescent children born to teenage mothers. J Marriage Fam 56:325-340.

Koob GF, Sanna PP, Bloom FE (1998) Neuroscience of addiction. Neuron 21:467-476.

Lende DH, Smith EO (2002) Evolution meets biopsychosociality: an analysis of addictive behavior. Addiction 97:447-458.

Lim MM, Nair HP, Young LJ (2005) Species and sex differences in brain distribution of corticotropin-releasing factor receptor subtypes 1 and 2 in monogamous and promiscuous vole species. J Comp Neurol 487:75-92.

Lim MM, Young LJ (2004) Vasopressin-dependent neural circuits underlying pair bond formation in the monogamous prairie vole. Neuroscience 125:35-45.

Liu Y, Wang ZX (2003) Nucleus accumbens oxytocin and dopamine interact to regulate pair bond formation in female prairie voles. Neuroscience 121:537-544.

Nestler EJ (2001) Molecular basis of long-term plasticity underlying addiction. Nat Rev Neurosci 2:215215.

Orsini C, Buchini F, Piazza PV, Puglisi-Allegra S, Cabib S (2004) Susceptibility to amphetamine-induced place preference is predicted by locomotor response to novelty and amphetamine in the mouse. Psychopharmacology (Berl) 172:264-270.

Panksepp J, Knutson B, Burgdorf J (2002) The role of brain emotional systems in addictions: a neuro-evolutionary perspective and new "self-report" animal model. Addiction 97:459-469.

Panksepp J, Nelson E, Bekkedal M (1997) Brain systems for the mediation of social separation-distress and social-reward: Evolutionary antecedents and neuropeptide intermediaries. Ann N Y Acad Sci 807:78-100.

Paxinos G, Watson C (1998) The rat brain in stereotaxic coordinates, fourth edition. New York: Academic Press.

Recio Adrados J-L (1995) The influence of family, school, and peers on adolescent drug misuse. Int J Addict 30:1407-1423.

Saal D, Dong Y, Bonci A, Malenka RC (2003) Drugs of abuse and stress trigger a common synaptic adaptation in dopamine neurons. Neuron 37:577-582.
Self DW, Barnhart WJ, Lehman DA, Nestler EJ (1996) Opposite modulation of cocaine-seeking behavior by D1- and D2-like dopamine receptor agonists. Science 271:1586-1589.

Self DW, Genova LM, Hope BT, Barnhart WJ, Spencer JJ, Nestler EJ (1998) Involvement of cAMP-dependent protein kinase in the nucleus accumbens in cocaine self-administration and relapse of cocaine-seeking behavior. J Neurosci 18:1848-1859.

Shapiro LE, Dewsbury DA (1990) Differences in affiliative behavior, pair bonding, and vaginal cytology in two species of vole (Microtus ochrogaster and M. montanus). J Comp Psychol 104:268-274.

Sved AF, Curtis JT (1993) Amino acid neurotransmitters in nucleus tractus solitarius: an in vivo microdialysis study. J Neurochem 61:2089-2098.

Wang Z (1995) Species differences in the vasopressin-immunoreactive pathways in the bed nucleus of the stria terminalis and medial amygdaloid nucleus in prairie voles (Microtus ochrogaster) and meadow voles (Microtus pennsylvanicus). Behav Neurosci 109: 305-311.

Wang Z, Smith W, Major DE, De Vries GJ (1994) Sex and species differences in the effects of cohabitation on vasopressin expression in the bed nucleus of the stria terminalis in prairie voles (Microtus ochrogaster) and meadow voles (Microtus pennsylvanicus). Brain Res 650:212-218.

Wang Z, Yu G, Cascio C, Liu Y, Gingrich B, Insel TR (1999) Dopamine $\mathrm{D} 2$ receptor-mediated regulation of partner preferences in female prairie voles (Microtus ochrogaster): a mechanism for pair bonding? Behav Neurosci 113:602-611.

Weatherford SC, Greenberg D, Gibbs J, Smith GP (1990) The potency of D-1 and D-2 receptor antagonists is inversely related to the reward value of sham-fed corn-oil and sucrose in rats. Pharmacol Biochem Behav 37:317-323.

Williams JR, Catania KC, Carter CS (1992) Development of partner preferences in female prairie voles (Microtus ochrogaster): the role of social and sexual experience. Horm Behav 26:339-349.

Yamaguchi K, Kandel DB (1985) On the resolution of role incompatibility: a life event history analysis of family roles and marijuana use. Am J Sociol 90:1284-1325.

Young AM, Rees KR (1998) Dopamine release in the amygdaloid complex of the rat, studied by brain microdialysis. Neurosci Lett 249:49-52.

Yun IA, Wakabayashi KT, Fields HL, Nicola SM (2004) The ventral tegmental area is required for the behavioral and nucleus accumbens neuronal firing responses to incentive cues. J Neurosci 24:2923-2933.

Yurek DM, Hipkens SB, Hebert MA, Gash DM, Gerhardt GA (1998) Age-related decline in striatal dopamine release and motoric function in brown Norway/Fischer 344 hybrid rats. Brain Res 791: 246-256.

Zocchi A, Girlanda E, Varnier G, Sartori I, Zanetti L, Wildish GA, Lennon M, Mugnaini M, Heidbreder CA (2003) Dopamine responsiveness to drugs of abuse: A shell-core investigation in the nucleus accumbens of the mouse. Synapse 50:293-302. 